\title{
Interactions Between Paracetamol and Hypromellose in the Solid State
}

\author{
Edyta Leyk and Marek Wesolowski* \\ Department of Analytical Chemistry, Medical University of Gdansk, Gdansk, Poland
}

Hydroxypropyl methylcellulose (hypromellose) is a widely known excipient commonly used in the preparation of drug formulations. It can interact with some active pharmaceutical ingredients (APIs), thereby contributing to a reduction in crystallinity, serve as a solvent for API or form stable dispersion with no tendency to aggregation. The aim of the present study was to investigate the effect of hypromellose on the solubility, miscibility and amorphization of paracetamol in mixture with this polymer. Homogenized mixtures of paracetamol with hypromellose were studied using differential scanning calorimetry (DSC), hot-stage microscopy (HSM), Fourier transform infrared (FT-IR) and Raman methods to obtain a deeper insight into the interactions between ingredients in solid state including phase diagram construction for crystalline API and amorphous polymer. A DSC study revealed potential interaction between ingredients resulting in reduced paracetamol crystallinity. This was proved using heating-cooling-heating test to confirm paracetamol amorphization. FT-IR and Raman investigations excluded chemical reaction and hydrogen bonding between ingredients. The phase diagram developed facilitates predictions on the solubility of API in polymer, on the mutual miscibility of ingredients and on the temperature of mixture glass transition.

Reviewed by:

Marcello Locatelli, Università degli Studi G. d'Annunzio

Chieti e Pescara, Italy Ashok K. Sundramoorthy, SRM Institute of Science and Technology, India

*Correspondence: Marek Wesolowski marwes@gumed.edu.pl

Specialty section: This article was submitted to Experimental Pharmacology and Drug Discovery,

a section of the journal Frontiers in Pharmacology

Received: 08 October 2018 Accepted: 07 January 2019 Published: 24 January 2019

Citation: Leyk E and Wesolowski M (2019) Interactions Between Paracetamol and Hypromellose in the Solid State.

Keywords: paracetamol, hypromellose, interactions, phase diagram, solubility with polymer, miscibility with polymer, glass transition in mixture

\section{INTRODUCTION}

Hydroxypropyl methylcellulose (hypromellose, HPMC, MHPC) is a widely known excipient used in the pharmaceutical industry for preparing oral, ophthalmic, nasal and topical formulations (Rowe et al., 2009). As shown in Figure 1A, hypromellose is not chemically well-defined, described rather as a partly $\mathrm{O}$-methylated and $\mathrm{O}$-(2-hydroxypropylated) cellulose. The $-\mathrm{OH}$ groups of polymer can undergo interaction with - $\mathrm{COOH}$ groups of active pharmaceutical ingredient (API) leading to hydrogen bonding, which is more stable than those formed between -OH groups of water and polymer (Yao et al., 2011). For commercial purposes, hypromellose is available in several grades that vary in viscosity and extent of substitution. As a non-toxic, biodegradable and hydrophilic polymer, hypromellose has recently been used for the development of new formulations such as the sustained-release mucosa adhesive, controlled-release pellets, microcapsules and variety of matrix, multilayers and coating sustained-release and controlled-release formulations (Rowe et al., 2009). It is also characterized by high swellability, which significantly effects the release kinetics of incorporated API (Siepmann and Peppas, 2001). Upon contact with water or biological fluid, the API diffuses into the device, resulting in polymer chain relaxation with volume expansion. Subsequently, the incorporated API diffuses out of the system.

The literature data has revealed that hypromellose can interact with some APIs, e.g., hypromellose forms a complex with ofloxacin (Subhashree et al., 2011). Fourier transform infrared 
(FT-IR) and Raman spectroscopic investigations suggested chemical interaction in formulation leading to hydrogen bonding and esterification. Powder X-ray diffraction (PXRD) and scanning electron microscopy (SEM) data revealed that the crystalline nature of ofloxacin in formulation is stable and would lead to increased stability and API loading, decreasing solubility and delaying release of ofloxacin from polymeric suspension with improved bioavailability and penetration capacity. The study on sustained-release tablets and water solutions with carbamazepine revealed that hypromellose inhibits the transformation of API to its dihydrate in the gel layer of hydrated tablets and water solutions and induces amorphization of API crystals (Katzhendler et al., 1998). This may be due to hydrogen bonding, the $-\mathrm{OH}$ groups of polymer possibly attaching to carbamazepine at the site of water binding. Thus, transformation of API to dihydrate is inhibited. The study on nicotinamide mixtures with hypromellose using differential scanning calorimetry (DSC) and PXRD analyses showed that the polymer dissolves in fused API at $140^{\circ} \mathrm{C}$ (Hino and Ford, 2001). It leads to a decrease in crystallinity and an increase in glass transition temperature of the cooled mixtures as the weight fraction of polymer increased. Dissolution of hypromellose in molten API was accompanied by hydrogen bonding confirmed by FT-IR. The FT-IR, XRDP, and DSC methods were also used to explain the mechanism of formation of amorphous white film on tablets, when the coating solution included hypromellose and calcium lactate pentahydrate (Sakata et al., 2006). The results confirmed the interaction of polymer atoms with ionic calcium.

A brief specification of hypromellose interactions with APIs proved that the polymer helps to reduce the crystallinity of API depending on concentration (Katzhendler et al., 1998; Friedrich et al., 2005; Bajdik et al., 2008; Bhise and Rajkumar, 2008; Zaini et al., 2014; Oh et al., 2015; Chonkar et al., 2016), that it dissolves in fused API (Hino and Ford, 2001) or that APIs dissolve in the polymer (Tian et al., 2015; Baghel et al., 2016), and that it is able to form stable dispersion with no tendency to aggregation (miscibility with APIs) (Marsac et al., 2006; Meng et al., 2015; Tian et al., 2015; Baghel et al., 2016). The formation of hydrogen bonding with APIs is also suggested in many studies (Katzhendler et al., 1998; Subhashree et al., 2011). It should be emphasized that hypromellose contains a large number of hydrogen bonding groups, hence its strong influence over the modification of the crystal habit (Raghavan et al., 2001). Taking all the above into consideration, the purpose of this study was to investigate the effect of hypromellose on the solubility, miscibility and amorphization of paracetamol in mixture with this polymer. Therefore, homogenized mixtures of paracetamol with hypromellose were studied using DSC, hotstage microscopy (HSM), FT-IR and Raman methods to obtain a fuller understanding of the interactions between ingredients in solid state, including phase diagram construction for crystalline API and amorphous polymer. As far as the authors are aware, this is one of the first studies in which the interactions between paracetamol and hypromellose in the solid state have been evaluated through the methodology outlined below.

Paracetamol (as marketed in Europe, acetaminophen in the USA and Asia), was chosen for the study because it is the most widely used over-the-counter analgesic (pain reliever) and antipyretic (fever reducer) (Bennett and Brown, 2008). Chemically, it is $N$-(4-hydroxyphenyl) acetamide, which formula is presented in Figure 1B. A study on the structure of molecule and crystal of paracetamol revealed that hydrogen bonds only exist among molecules, i.e., API crystal consists of the $-\mathrm{OH} \cdots \mathrm{O}=\mathrm{C}$ and $-\mathrm{NH} \cdots \mathrm{OH}$ hydrogen bonding (An et al., 2008). The majority of paracetamol formulations are available on the pharmaceutical market in solid dosage forms such as classical, coated and uncoated tablets, tablets with prolonged action, capsules containing powders, pellets or granulates with prolonged release, dragées, and suppositories. There are also liquid dosage forms such as ophthalmic preparations and suspensions for children. Paracetamol in solid dosage forms is used both in single-ingredient formulations, and in combination with opioids (codeine, dihydrocodeine, oxycodone, tramadol), non-steroid anti-inflammatory drugs (ibuprofen), psycholeptics (WHO Collaborating Centre for Drug Statistics Methodology, 2018) and antispasmodic drug (eperisone

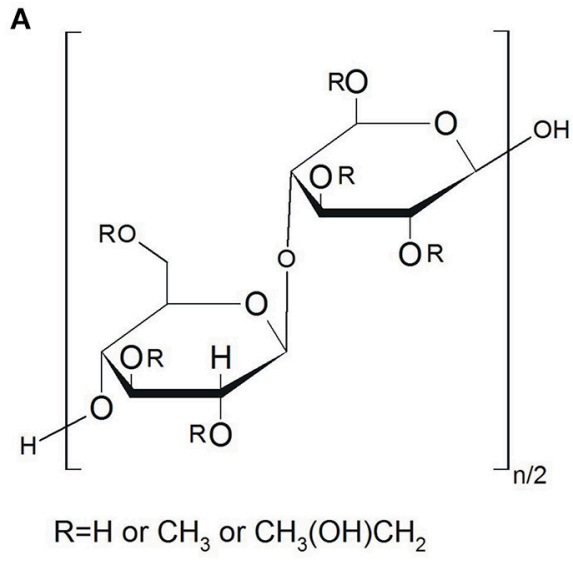

B<smiles>CC(=O)Nc1ccc(O)cc1</smiles>

FIGURE 1 | Chemical structure of (A) hypromellose and (B) paracetamol. 
hydrochloride) (Locatelli et al., 2015). Hypromellose is one of the main excipients commonly used for preparation of solid formulations with paracetamol. Recently, extensive studies have been performed on solid-state characterization of paracetamol metastable polymorphic form formed in binary mixtures with hypromellose (Rossi et al., 2003) and thermal behavior of paracetamol in binary mixtures with this polymer (Giordano et al., 2002). It has been revealed that only amorphous paracetamol is present in hypromellose mixtures with API content below 75\%, after the cooling phase. Moreover, review papers have also been published on thermal analyses of hypromellose powder, gels and matrix tablets (Ford and Mitchell, 1995; Ford, 1999).

\section{MATERIALS AND METHODS}

\section{Materials}

Hypromellose (purity $\geq 99 \%$ ) and paracetamol (purity $\geq 99 \%$ ) were obtained from Sigma-Aldrich (Steinheim, Germany). Both hypromellose and paracetamol were used in this study as received.

Binary physical mixtures of API and excipient consisting of $5,10,20,30,40,50,60,70,80,90$, and $95 \%$ of paracetamol were prepared by a gentle mixing of ingredients in a porcelain mortar using a plastic spatula and a pestle. An analytical balance model XA 105 Dual Range (Mettler Toledo, Schwerzenbach, Switzerland), was used to weigh the paracetamol

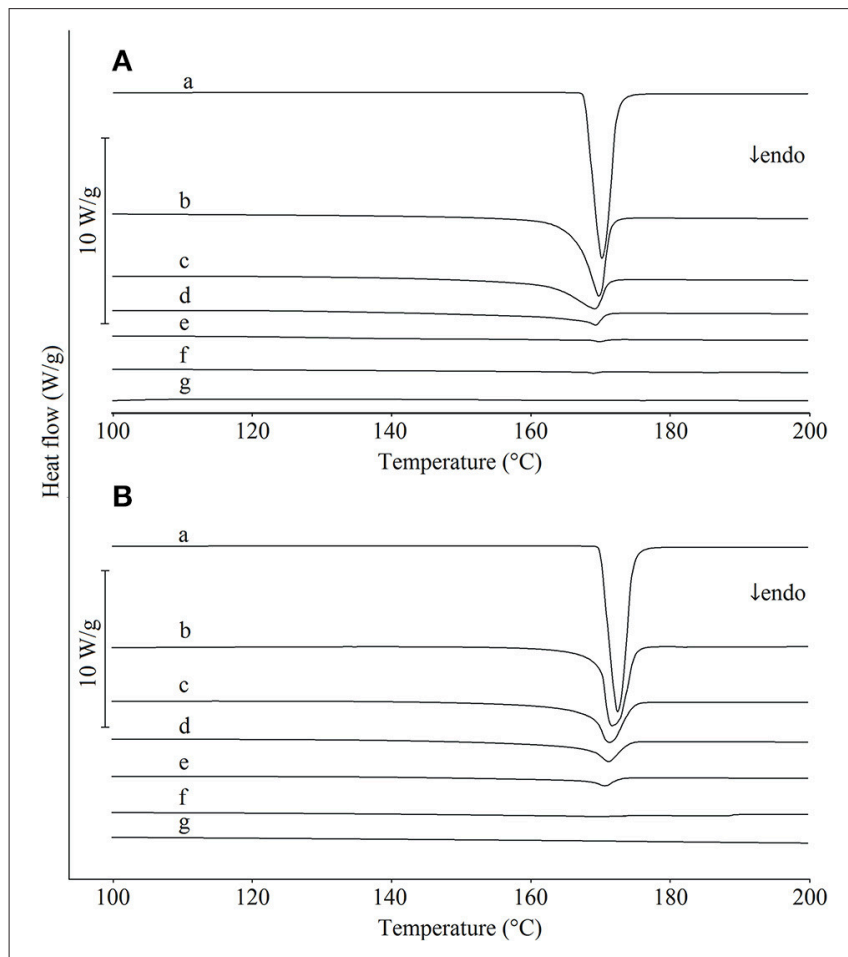

FIGURE 2 | DSC curves for (a) paracetamol, (g) hypromellose and their mixtures containing (b) $80 \%$, (c) $60 \%$, (d) $40 \%$, (e) $20 \%$, and (f) $10 \%$ of paracetamol. Mixtures mixed with $(\mathbf{A})$ a plastic spatula and (B) a pestle. and hypromellose. To achieve complete homogenization, API and excipient were thoroughly mixed over a period of $10 \mathrm{~min}$.

\section{Methods}

DSC curves were recorded on a heat-flux DSC $822^{\mathrm{e}}$ instrument (Mettler Toledo, Schwerzenbach, Switzerland), with a liquid nitrogen cooling system (Dewar vessel) and STAR ${ }^{\mathrm{e}} 9.10$ software. The samples, $\sim 4 \mathrm{mg}$ in weight, were accurately weighed $( \pm 0.01 \mathrm{mg})$ and placed in $40 \mu \mathrm{l}$ flat-bottomed aluminum pans with crimped-on lids. Measurements in triplicate were performed over the temperature range of 25 to $300^{\circ} \mathrm{C}$ at a heating rate $10^{\circ} \mathrm{C} / \mathrm{min}$ under nitrogen stream (purity 99.9997\%, Air Products, Warsaw, Poland) at a flux rate of $70 \mathrm{ml} / \mathrm{min}$.

A heating-cooling-heating test was carried out using the following temperature program: heating samples at a rate of $10^{\circ} \mathrm{C} / \mathrm{min}$ from 25 to $250^{\circ} \mathrm{C}$, isotherm for $2 \mathrm{~min}$, cooling at a rate $40^{\circ} \mathrm{C} / \mathrm{min}$ from 250 to $-25^{\circ} \mathrm{C}$, isotherm for $2 \mathrm{~min}$ and the second heating at a rate $10^{\circ} \mathrm{C} / \mathrm{min}$ to $250^{\circ} \mathrm{C}$.

Indium (In, purity 99.999\%) and zinc (Zn, purity 99.998\%) standards (Mettler Toledo, Schwerzenbach, Switzerland) were used to calibrate a DSC cell. Reference values for onset temperature and heat flow were as follows: $156.6^{\circ} \mathrm{C}$ and $28.45 \mathrm{~J} / \mathrm{g}$ (In); $419.6^{\circ} \mathrm{C}$ and $107.5 \mathrm{~J} / \mathrm{g}(\mathrm{Zn})$, and for those measured: $156.6^{\circ} \mathrm{C}$ and $28.80 \mathrm{~J} / \mathrm{g}(\mathrm{In}) ; 420.1^{\circ} \mathrm{C}$ and $110.7 \mathrm{~J} / \mathrm{g}(\mathrm{Zn})$.

A HSM equipped with a BX41polarizing microscope (Olympus, Shinjuku, Japan) and a color video digital camera SC30 supported by Olympus CellA software was used to record imagines during temperature scans. A $1-5 \mathrm{mg}$ of sample was placed between two glass cover slides and put on a hot stage (Semic, Bioelektronika, Krakow, Poland) equipped with an SR90 temperature regulator (Shimaden, Tokio, Japan) and Heating Desk Shimaden software. Measurements were performed over the temperature range of 25 to $300^{\circ} \mathrm{C}$ at a heating rate of $10^{\circ} \mathrm{C} / \mathrm{min}$.

FT-IR spectra were collected using a Nicolet 380 FT-IR spectrometer (Thermo Fischer Scientific, Madison, USA), with a DTGS $\mathrm{KBr}$ detector and OMNIC software. The samples analyzed were prepared as $\mathrm{KBr}$ pellets with the aid of a hydraulic press (Specac, Orpington, UK), each pellet being prepared from a 1 -mg sample and $100 \mathrm{mg}$ of spectroscopy-grade $\mathrm{KBr}$ (Merck, Darmstadt, Germany). Measurements in triplicate were performed in the 4,000-400 $\mathrm{cm}^{-1}$ spectral region with a spectral resolution of $4 \mathrm{~cm}^{-1}$. Prior to each measurement, background spectra was taken with an average of 16 scans.

Raman spectra were recorded on a DXR SmartRaman spectrometer (Thermo Fisher Scientific, Madison, USA). The instrument was equipped with a Raleigh filter, CCD detector and OMNIC software. Measurements were run in triplicate over a spectral range of 3413-99 $\mathrm{cm}^{-1}$ with resolution of $2 \mathrm{~cm}^{-1}$. A $15-$ mW DXR $780 \mathrm{~nm}$ laser with an aperture of $25 \mu \mathrm{m}$ was deployed. Exposure time was $1 \mathrm{~s}$ (twice).

\section{Calculations}

The solubility curve of crystalline API in an amorphous polymer was calculated in accordance with the procedure described in the literature (Tian et al., 2015; Baghel et al., 2016). If a polymer is considered as a solvent, the quantity of paracetamol soluble 
in hypromellose is expressed as the mole fraction $\left(x_{A P I}\right)$ of the dissolved API in relation to the activity coefficient $\left(\gamma_{A P I}\right)$, according to the equation:

$$
\ln x_{A P I}=\frac{\Delta H_{f u s}}{R T_{m}}\left(1-\frac{T m}{T}\right)-\ln \gamma_{A P I}
$$

where: $\Delta H_{f u s}$ is the melting enthalpy of paracetamol, $R$ the gas constant, $T_{m}$ the melting temperature of paracetamol in Kelvin, and $T$ the temperature in Kelvin of the two phases of paracetamol in equilibrium.

The activity coefficient $\left(\gamma_{\text {API }}\right)$ of paracetamol can be calculated on the basis of Hansen solubility parameters $(\delta)$, the molar volume $(V)$ of mixture ingredients $(k)$, the mixture volume $(\bar{V})$ and the molar volume of weighted Hansen solubility parameter $(\bar{\delta})$, according to the equation:

$$
\begin{aligned}
\ln \gamma_{A P I} & =\frac{V_{A P I}}{R T}\left\{\left(\delta_{d}^{A P I}-\bar{\delta}_{d}\right)^{2}+0,25\left[\left(\delta_{p}^{A P I}-\bar{\delta}_{p}\right)^{2}+\left(\delta_{h}^{A P I}-\bar{\delta}_{h}\right)^{2}\right]\right\} \\
& +\ln \frac{V_{A P I}}{\bar{V}}+1-\frac{V_{A P I}}{\bar{V}}
\end{aligned}
$$

The mixture volume $(\bar{V})$ and molar volume of weighted Hansen solubility parameter $(\bar{\delta})$, taking into account the character of interactions, i.e., dispersion forces $\left(\delta_{d}\right)$, polar interactions $\left(\delta_{p}\right)$ and hydrogen bonding $\left(\delta_{h}\right)$, can be calculated according to the following equations:

$$
\begin{aligned}
\bar{\delta}= & \sum_{k=1}^{n} \phi_{k} \delta_{k} \text { for } \bar{\delta}_{d}, \bar{\delta}_{p}, \bar{\delta}_{h}, \text { where } k \text { is the paracetamol } \\
& \text { or hypromellose } \\
\phi_{k}= & \frac{x_{k} V_{k}}{\bar{V}} \\
\bar{V}= & \sum_{k=1}^{n} x_{k} V_{k} \\
V_{k}= & \frac{M_{k}}{\rho_{k}}
\end{aligned}
$$

where $\phi$ is the volume fraction of API or polymer $(k), x$ the mole fraction, $M$ the molecular weight, and $\rho$ the density of ingredients.

The miscibility curve of paracetamol with hypromellose can be predicted based on the Florry-Huggins theory and the Gibbs

TABLE 1 | Regression parameters of calibration curves and limits of detection and determination of paracetamol methods in mixtures with hypromellose.

\begin{tabular}{lcc}
\hline Parameter & \multicolumn{2}{c}{ Hypromellose } \\
\cline { 2 - 3 } & Mixing with a spatula & Mixing with a pestle \\
\hline Paracetamol content (\%) & $5-95$ & $5-95$ \\
$\mathrm{a} \pm \Delta \mathrm{a}$ & $1.85 \pm 0.09$ & $1.81 \pm 0.17$ \\
$\mathrm{~S}_{\mathrm{a}}$ & 0.02 & 0.04 \\
$\mathrm{~b} \pm \Delta \mathrm{b}$ & $-12.39 \pm 5.81$ & $-37.45 \pm 10.16$ \\
$\mathrm{~S}_{\mathrm{b}}$ & 1.35 & 2.36 \\
$r$ & 0.9986 & 0.9986 \\
$\mathrm{~S}_{x y}$ & 2.83 & 2.74
\end{tabular}

free energy $\left(\Delta G_{\text {mix }}\right)$ (Forster et al., 2001; Djuris et al., 2013; Maniruzzaman et al., 2014; Tian et al., 2015). The Gibbs free energy $\left(\Delta G_{m i x}\right)$ of mixing both ingredients is described by the equation:

$\Delta G_{m i x}=R T\left[\phi_{A P I} \ln \phi_{A P I}+\frac{1-\phi_{A P I}}{n} \ln \left(1-\phi_{A P I}\right)+\chi \phi_{A P I}\left(1-\phi_{A P I}\right)\right]$

where $n$ is the number of API lattice sites, defined as the volume of API molecule occupied by a polymer chain, and $\chi$ is the API-polymer interaction parameter.

The number of API lattice sites occupied by a polymer chain $(n)$ and the API-polymer interaction parameter $(\chi)$ can be calculated by the following equations:

$$
\begin{aligned}
n & =\frac{V_{\text {polymer }}}{V_{A P I}} \\
\chi & =\frac{v\left(\delta_{A P I}-\delta_{\text {polymer }}\right)^{2}}{R T} \\
\delta_{k} & =\sqrt{\delta_{d}^{2}+\delta_{p}^{2}+\delta_{h}^{2}}
\end{aligned}
$$

where $v$ is the volume of paracetamol lattice site (volume of the $\mathrm{API}$ ), and $\delta$ is the Hansen solubility parameter $(\delta)$.

Miscibility curve (spinodal curve) can be predicted by setting the second derivative of the Gibbs free energy to zero, as expressed by the equation:

$$
T_{s}=\frac{2 v\left(\delta_{A P I}-\delta_{\text {polymer }}\right)^{2}}{R} * \frac{1}{\frac{1}{\phi_{A P I}}-\frac{1}{m\left(1-\phi_{A P I}\right)}}
$$

The glass transition curve can be predicted using the relation between the glass transition temperature $\left(T_{g}\right)$ of the mixture and the weight fraction of paracetamol $\left(w_{A P I}\right)$ in the mixture, according to the Fox equation (Tian et al., 2015):

$$
\frac{1}{T_{g}}=\frac{w_{A P I}}{T_{g_{A P I}}}+\frac{1-w_{A P I}}{T_{g_{\text {polymer }}}}
$$

where $T_{g}$ is the glass transition temperature of a mixture, $T_{g_{A P I}}$ and $T_{g_{\text {polymer }}}$ are the glass transition temperatures of paracetamol and hypromellose, respectively.

\section{RESULTS AND DISCUSSION}

Paracetamol may interact with other APIs or excipients when used together, e.g., many drug formulations including paracetamol and caffeine irrespective of the fact that both active ingredients form a eutectic mixture (Bi et al., 2003). Because hypromellose is commonly used as an important excipient in the fabrication of paracetamol drug formulations, the current study was carried out to assess potential interactions between ingredients mixed at differing mass ratios. 


\section{DSC of Paracetamol-Hypromellose Mixtures}

The DSC curves of paracetamol, hypromellose and their mixtures prepared by carefully mixing ingredients with a plastic spatula in a porcelain mortar are shown in Figure 2A, those mixed using a pestle in Figure 2B. The DSC curve of paracetamol (curve a) displays a single endothermic peak due to the melting of polymorphic form I (monoclinic) at $169.4^{\circ} \mathrm{C}$, which is consistent with the literature data (Klìmová and Leitner, 2012). The physical mixtures homogenized using a spatula (Figure 2A, curves b-f) revealed that the endothermic peak due to the melting of paracetamol appeared on the DSC curves over the entire concentration range and decreased as the content of active ingredient in the mixture decreased. By contrast, DSC curves for mixtures prepared using a pestle (Figure 2B, curves b-f) did not display the melting peak of paracetamol for mixtures containing $<20 \%$ of API. This suggests that the interaction between paracetamol and hypromellose resulted in a partial reduction in paracetamol crystallinity, probably due to intermolecular interaction with the formation of hydrogen bonding. As reported in the literature, other physical interactions are also possible, e.g., formation of eutectic mixtures (Bi et al., 2003), solid dispersions (Jahangiri et al., 2015), dissolution of paracetamol in hypromellose (Tian et al., 2015), reduction of paracetamol crystallinity in the presence of microcrystalline cellulose (de Oliveira et al., 2017) and amorphization or polymorphic transformation (Salunkhe et al., 2018). The risk of initiating interactions between ingredients is greater when homogenization of the mixtures is carried out using a pestle (Byard et al., 2005; Curtin et al., 2013).

The data compiled in Table 1 shows that the correlation coefficients between the enthalpy of paracetamol melting and the API content in mixtures with hypromellose are high. Detailed inspection of other regression parameters revealed high values of intercept $(b)$ in calibration equations for mixtures mixed using either plastic spatula or pestle. However, the intercept value increased approximately 3 -fold for mixtures mixed with a pestle as opposed to those mixed with a spatula. This may be indicative of the fact that the heat of fusion values are lower than those expected for real content of paracetamol in the mixtures. The implication is that the immediate cause of this situation may be a reduction in crystallinity of paracetamol due to its contact with hypromellose. The intensity of this process is enhanced by mixing the ingredients with a pestle.

\section{Hot-Stage Microscopy}

To investigate potential interactions between ingredients, HSM was also used. This technique is a combination of microscopy and thermal analysis to enable the investigation of solid state changes in substances of pharmaceutical interest under heating or cooling (Steger et al., 2012). It allows changes in appearance of paracetamol crystals, particles of amorphous hypromellose and their mixtures to be observed, along with the determination of characteristic temperatures.

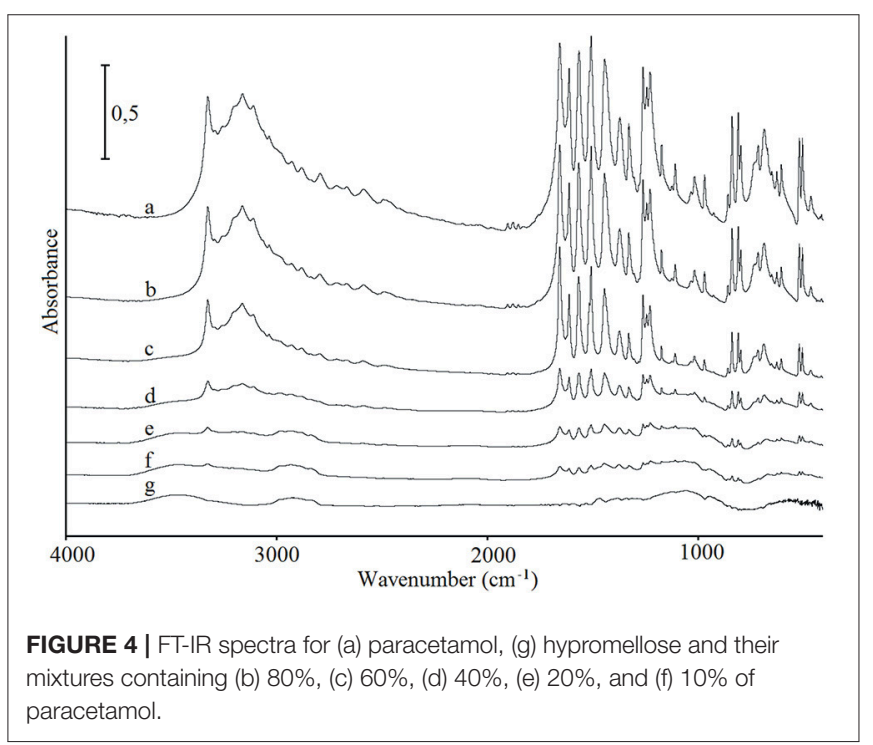

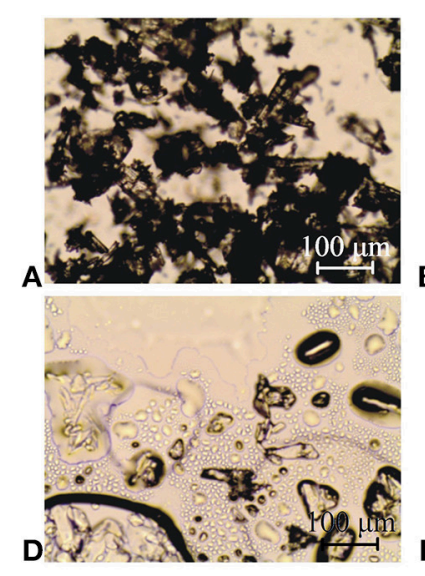
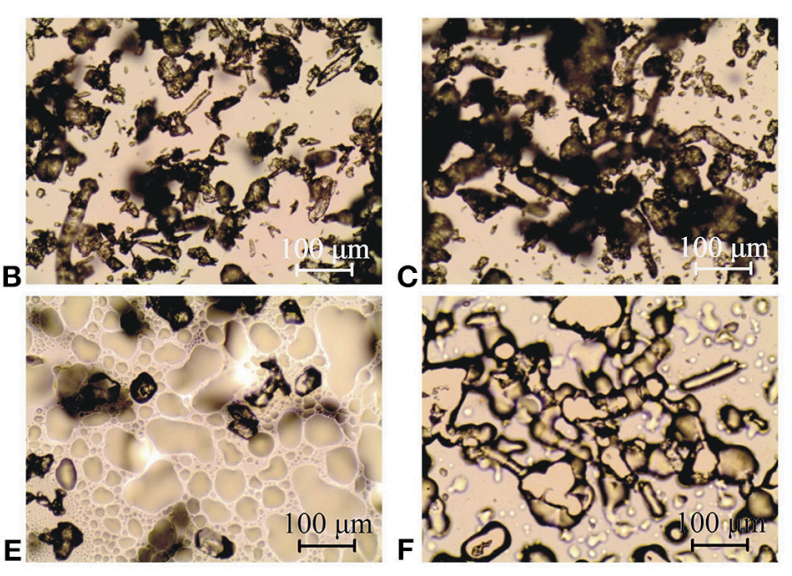

FIGURE 3 | HSM images of (A,D) paracetamol, (C,F) hypromellose and (B,E) their mixture at 1:1 mass ratio at ambient temperature (A-C), after melting of paracetamol $(\mathbf{D}, \mathbf{E})$ and after liquidation of hypromellose $\mathbf{( F )}$ 
The appearance of paracetamol, hypromellose and their mixture at a 1:1 mass ratio is shown in Figures 3A-C, respectively (ambient temperature), and Figures 3D,E (after melting of paracetamol) and Figure 3F (after liquidation of hypromellose). Image a reflects the fact that between ambient and sublimation temperature API crystals were characterized by regular shape but various sizes. Under heating, paracetamol sublimed above $150^{\circ} \mathrm{C}$, and subsequently, its small crystals melted at $\sim 168^{\circ} \mathrm{C}$. Vapors of API sublimation solidified to form needle-like crystals on the cool surface. FT-IR used to investigate these crystals confirmed the existence of form I of paracetamol. DSC analyses revealed that the needle-like crystals melted at $168^{\circ} \mathrm{C}$, which corroborates the melting of form I of paracetamol (Klìmová and Leitner, 2012). Complete melting of API and its intensive evaporation were observed above $172^{\circ} \mathrm{C}$ (image d). Under cooling to ambient temperature, the sample crystallized. On the other hand, image c presents particles of amorphous hypromellose at various sizes. Under heating, liquidation and browning of the polymer were observed at $\sim 260^{\circ} \mathrm{C}$ (Figure 3F).

A HSM study revealed that at the initial stage of the heating process, API crystals and particles of amorphous polymer were easily visible (Figure 3B) in mixtures containing 10, 30, 50, 70, and $90 \%$ of paracetamol. Next, as with paracetamol heating, the sublimation of mixtures commenced at $\sim 150^{\circ} \mathrm{C}$. Afterwards, the melting of the finest crystals began at temperatures lower than that of paracetamol, i.e., 162, 161, 159, 157, and $156^{\circ} \mathrm{C}$, respectively, for mixtures with decreasing content of API. Figure 3E presents the $1: 1$ mass ratio mixture heated to $159^{\circ} \mathrm{C}$ and shows hypromellose particles and melted paracetamol. In brief, neither new crystals nor amorphous particles were found when the mixtures were heated.

\section{FT-IR and Raman Spectroscopy}

FT-IR and Raman spectroscopy were used to investigate whether any intermolecular interactions or chemical reactions may have occurred between paracetamol and hypromellose. Figure 4

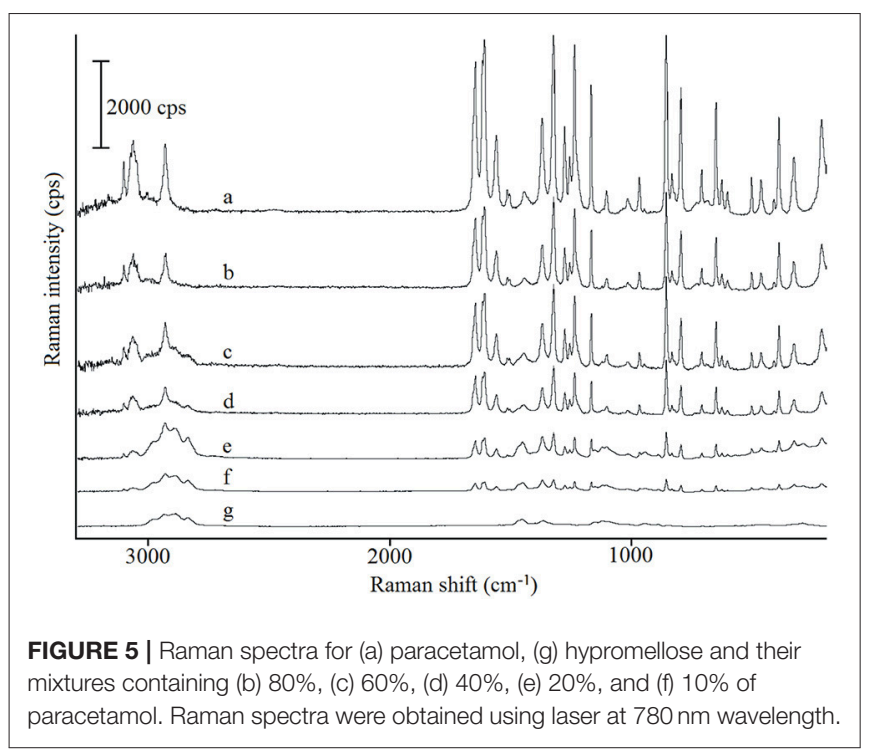

shows the FT-IR spectra of paracetamol, hypromellose, and their mixtures. In interpreting these data, special attention was paid to the characteristic bands of chemical groups capable of forming hydrogen bonding. Characteristic bands for monoclinic paracetamol (spectrum a) were found at $808 \mathrm{~cm}^{-1}$ (amid group deformation), 968 and $1,259 \mathrm{~cm}^{-1}$ (C-N stretching vibrations), $1,655 \mathrm{~cm}^{-1}$ (C=O stretching and $\mathrm{C}-\mathrm{NH}$ deformation), 3,034 $\mathrm{cm}^{-1}\left(\mathrm{~N}-\mathrm{H}\right.$ stretching) and 3,161 and $3,325 \mathrm{~cm}^{-1}(\mathrm{O}-\mathrm{H}$ stretching) (Burgina et al., 2004; An et al., 2008). This confirms the results of DSC analysis which indicates that form I of paracetamol is the API under investigation (Burgina et al., 2004; Łuczak et al., 2013). Detailed inspection of the FT-IR data for mixtures (spectra $b-f$ ) revealed that characteristic absorption bands of paracetamol were found in all the spectra. Their intensity decreases proportionate to decreasing paracetamol content in the mixtures. Moreover, the lack of shifting in the characteristic absorption bands of both ingredients in conjunction with a lack of new bands suggests that neither physical interaction nor chemical reaction occurred between ingredients. It concurs with the literature data which revealed that hydrogen bonds have not been formed between ingredients in the physical mixtures, but they can be formed during hot-melt extrusion, e.g., nimodipine with hydroxypropyl methylcellulose succinate acetate (Zhang et al., 2018). It has also been confirmed that shifting of $\mathrm{NH}$ band at $3,300 \mathrm{~cm}^{-1}$ to $3,357 \mathrm{~cm}^{-1}$ in the spectrum of nimodipine extrudate with polymer strongly evidenced the formation of hydrogen bonds between the amine and carbonyl groups of API and polymer, respectively. The hydrogen bonds can also be created in the presence of solvent, e.g., using aqueous polymer solutions (Wen et al., 2005) or during electrospray-drying (Liu et al., 2018).

The Raman spectra of paracetamol, hypromellose and their mixtures are shown in Figure 5. Characteristic bands for paracetamol (spectrum a) were found at $463 \mathrm{~cm}^{-1}$ (out-ofplane ring deformation), $1,235 \mathrm{~cm}^{-1}$ (C-N stretching vibration), $1,560 \mathrm{~cm}^{-1}\left(\mathrm{~N}-\mathrm{H}\right.$ and $\mathrm{C}=\mathrm{O}$ stretching), and $1,646 \mathrm{~cm}^{-1}$ ( $\mathrm{C}=\mathrm{O}$ stretching) (Burgina et al., 2004). Raman shift at 463 $\mathrm{cm}^{-1}$ is particularly characteristic of the polymorphic form

TABLE 2 | Parameters used to develop a phase diagram.

\begin{tabular}{|c|c|c|}
\hline Parameter & Hypromellose & Paracetamol \\
\hline Molar mass (g/mol) & 10,000 & 151.16 (Espeau et al., 2005) \\
\hline Density $\left(\mathrm{g} / \mathrm{cm}^{3}\right)$ & 1.0 (Chan et al., 2006) & 1.3 (Espeau et al., 2005) \\
\hline Enthalpy of melting $(\mathrm{J} / \mathrm{mol})$ & - & 29716 \\
\hline Molar volume $\left(\mathrm{cm}^{3} / \mathrm{mol}\right)$ & - & 139.0 (Chan et al., 2006) \\
\hline Volume of a lattice $\left(\AA^{3}\right)$ & - & 772.26 (Adhikari et al., 2015) \\
\hline Glass transition $(\mathrm{K})$ & 433.15 & 296 (Djuris et al., 2013) \\
\hline Melting (K) & - & 447.9 (Sibik et al., 2014) \\
\hline \multicolumn{3}{|c|}{ SOLUBILITY PARAMETERS (MPa) ${ }^{1 / 2}$} \\
\hline$\delta_{d}$ & $\begin{array}{c}16.95 \text { (Chan et al., } \\
\text { 2006) }\end{array}$ & 20.74 (Chan et al., 2006) \\
\hline$\delta_{\mathrm{p}}$ & 8.55 (Chan et al., 2006) & 12.7 (Chan et al., 2006) \\
\hline$\delta_{\mathrm{h}}$ & 9.04 (Chan et al., 2006) & 17.49 (Chan et al., 2006) \\
\hline$\delta$ & 21.03 & 29.96 \\
\hline
\end{tabular}

References are given in the parentheses. 
I of paracetamol in contrast to that at $454 \mathrm{~cm}^{-1}$ which is characteristic of form II (An et al., 2008). Thus, similar to the DSC and FT-IR data, form I of paracetamol has also been identified by Raman spectroscopy. Detailed inspection of the data for all API mixtures (spectra b-f) confirmed that the existence of characteristic Raman shifts is related to paracetamol. The intensity of these bands decreases in line with decreased paracetamol content in the mixtures. Under no circumstances did bands shift or new bands appear. Therefore, neither physical interactions nor chemical reactions between ingredients were to be expected.

\section{Phase Diagram for Paracetamol and Hypromellose}

The classical phase diagram is constructed using the melting temperatures of two ingredients existing in a crystal form.
Hypromellose is an amorphous polymer that does not melt, but is characterized by glass transition. Preparation of the phase diagram for a mixture of crystalline API and amorphous polymer entails the calculation of three curves which predict the solubility of API in polymer, mutual miscibility of ingredients and temperature of glass transition. The phase diagram reflects an equilibrium state predicted from the calculations and enables the conclusions to be drawn relating to the quantity of API (that may be dissolved in polymer at a given temperature) and about the composition of the mixture characterized by complete miscibility at a given temperature.

The literature data used for calculations of the solubility, miscibility, and glass transition curves in equations 1,11 , and 12 (Calculations section) are listed in Table 2 (Espeau et al., 2005; Chan et al., 2006; Sibik et al., 2014; Adhikari et al., 2015), while the calculated values predicting the solubility of

TABLE 3 | Calculated quantities of paracetamol that can be dissolved in hypromellose in relation to the temperature.

\begin{tabular}{|c|c|c|c|c|c|c|c|c|c|c|c|c|c|c|c|c|c|}
\hline \multirow{2}{*}{$\begin{array}{l}\text { Quantity of } \\
\text { paracetamol (\%) }\end{array}$} & \multicolumn{17}{|c|}{ Temperature $\left({ }^{\circ} \mathrm{C}\right)$} \\
\hline & 0 & 10 & 20 & 30 & 40 & 50 & 60 & 70 & 80 & 90 & 100 & 110 & 120 & 130 & 140 & 150 & 160 \\
\hline 95 & 0.75 & 1.20 & 1.84 & 2.75 & 4.01 & 5.71 & 7.97 & 10.89 & 14.63 & 19.34 & 25.18 & 32.34 & 41.01 & 51.39 & 63.71 & 78.17 & 95.02 \\
\hline 90 & 0.71 & 1.13 & 1.74 & 2.60 & 3.79 & 5.40 & 7.53 & 10.30 & 13.84 & 18.29 & 23.83 & 30.61 & 38.82 & 48.65 & 60.32 & 74.03 & \\
\hline 85 & 0.67 & 1.06 & 1.63 & 2.44 & 3.56 & 5.08 & 7.09 & 9.70 & 13.04 & 17.24 & 22.46 & 28.86 & 36.62 & 45.91 & 56.94 & 69.90 & \\
\hline 80 & 0.62 & 0.99 & 1.53 & 2.29 & 3.34 & 4.76 & 6.64 & 9.10 & 12.24 & 16.19 & 21.10 & 27.13 & 34.44 & 43.20 & 53.59 & 65.82 & \\
\hline 75 & 0.58 & 0.92 & 1.42 & 2.13 & 3.11 & 4.44 & 6.21 & 8.51 & 11.45 & 15.16 & 19.77 & 25.43 & 32.30 & 40.54 & 50.32 & 61.82 & \\
\hline 70 & 0.54 & 0.85 & 1.32 & 1.98 & 2.90 & 4.14 & 5.78 & 7.93 & 10.68 & 14.15 & 18.48 & 23.78 & 30.22 & 37.95 & 47.13 & 57.94 & \\
\hline 65 & 0.49 & 0.79 & 1.22 & 1.83 & 2.68 & 3.84 & 5.37 & 7.37 & 9.94 & 13.18 & 17.22 & 22.18 & 28.21 & 35.45 & 44.06 & 54.19 & \\
\hline 60 & 0.45 & 0.73 & 1.12 & 1.69 & 2.48 & 3.55 & 4.98 & 6.84 & 9.23 & 12.25 & 16.02 & 20.65 & 26.28 & 33.05 & 41.10 & 50.60 & \\
\hline 55 & 0.42 & 0.67 & 1.03 & 1.56 & 2.29 & 3.28 & 4.60 & 6.33 & 8.55 & 11.36 & 14.87 & 19.18 & 24.44 & 30.76 & 38.28 & 47.16 & \\
\hline 50 & 0.38 & 0.61 & 0.95 & 1.43 & 2.10 & 3.02 & 4.24 & 5.84 & 7.90 & 10.51 & 13.77 & 17.79 & 22.69 & 28.58 & 35.60 & 43.90 & \\
\hline 45 & 0.35 & 0.56 & 0.87 & 1.31 & 1.93 & 2.78 & 3.90 & 5.39 & 7.29 & 9.71 & 12.74 & 16.48 & 21.03 & 26.52 & 33.07 & 40.80 & \\
\hline 40 & 0.31 & 0.51 & 0.79 & 1.20 & 1.77 & 2.55 & 3.59 & 4.96 & 6.72 & 8.96 & 11.77 & 15.24 & 19.47 & 24.58 & 30.67 & 37.89 & \\
\hline 35 & 0.29 & 0.46 & 0.72 & 1.09 & 1.62 & 2.33 & 3.29 & 4.55 & 6.18 & 8.26 & 10.86 & 14.07 & 18.00 & 22.75 & 28.42 & & \\
\hline 30 & 0.26 & 0.42 & 0.66 & 1.00 & 1.48 & 2.13 & 3.02 & 4.18 & 5.68 & 7.60 & 10.00 & 12.98 & 16.63 & 21.04 & 26.31 & & \\
\hline 25 & 0.23 & 0.38 & 0.60 & 0.91 & 1.35 & 1.95 & 2.76 & 3.83 & 5.22 & 6.99 & 9.21 & 11.97 & 15.35 & 19.44 & 24.34 & & \\
\hline 20 & 0.21 & 0.34 & 0.54 & 0.82 & 1.23 & 1.78 & 2.52 & 3.51 & 4.78 & 6.42 & 8.47 & 11.02 & 14.15 & 17.94 & & & \\
\hline 19 & 0.21 & 0.34 & 0.53 & 0.81 & 1.20 & 1.75 & 2.48 & 3.44 & 4.70 & 6.31 & 8.33 & 10.84 & 13.92 & 17.66 & & & \\
\hline 18 & 0.20 & 0.33 & 0.52 & 0.79 & 1.18 & 1.71 & 2.43 & 3.38 & 4.62 & 6.20 & 8.19 & 10.66 & 13.70 & 17.38 & & & \\
\hline 17 & 0.20 & 0.32 & 0.51 & 0.78 & 1.16 & 1.68 & 2.39 & 3.32 & 4.54 & 6.09 & 8.05 & 10.49 & 13.47 & & & & \\
\hline 16 & 0.19 & 0.32 & 0.50 & 0.76 & 1.14 & 1.65 & 2.35 & 3.27 & 4.46 & 5.99 & 7.92 & 10.31 & 13.26 & & & & \\
\hline 15 & 0.19 & 0.31 & 0.49 & 0.75 & 1.12 & 1.62 & 2.30 & 3.21 & 4.38 & 5.89 & 7.78 & 10.14 & 13.04 & & & & \\
\hline 14 & 0.19 & 0.30 & 0.48 & 0.73 & 1.09 & 1.59 & 2.26 & 3.15 & 4.31 & 5.79 & 7.65 & 9.98 & 12.83 & & & & \\
\hline 13 & 0.18 & 0.30 & 0.47 & 0.72 & 1.07 & 1.56 & 2.22 & 3.09 & 4.23 & 5.69 & 7.52 & 9.81 & 12.62 & & & & \\
\hline 12 & 0.18 & 0.29 & 0.46 & 0.71 & 1.05 & 1.53 & 2.18 & 3.04 & 4.16 & 5.59 & 7.40 & 9.65 & & & & & \\
\hline 11 & 0.17 & 0.29 & 0.45 & 0.69 & 1.03 & 1.50 & 2.14 & 2.99 & 4.08 & 5.49 & 7.27 & 9.49 & & & & & \\
\hline 10 & 0.17 & 0.28 & 0.44 & 0.68 & 1.01 & 1.48 & 2.10 & 2.93 & 4.01 & 5.40 & 7.15 & 9.33 & & & & & \\
\hline 9 & 0.17 & 0.27 & 0.43 & 0.67 & 0.99 & 1.45 & 2.06 & 2.88 & 3.94 & 5.31 & 7.03 & & & & & & \\
\hline 8 & 0.16 & 0.27 & 0.42 & 0.65 & 0.98 & 1.42 & 2.03 & 2.83 & 3.87 & 5.21 & 6.91 & & & & & & \\
\hline 7 & 0.16 & 0.26 & 0.42 & 0.64 & 0.96 & 1.39 & 1.99 & 2.78 & 3.81 & 5.12 & & & & & & & \\
\hline 6 & 0.16 & 0.26 & 0.41 & 0.63 & 0.94 & 1.37 & 1.95 & 2.73 & 3.74 & 5.04 & & & & & & & \\
\hline 5 & 0.15 & 0.25 & 0.40 & 0.62 & 0.92 & 1.34 & 1.92 & 2.68 & 3.67 & 4.95 & & & & & & & \\
\hline 4 & 0.15 & 0.25 & 0.39 & 0.60 & 0.90 & 1.32 & 1.88 & 2.63 & 3.61 & & & & & & & & \\
\hline 3 & 0.15 & 0.24 & 0.38 & 0.59 & 0.89 & 1.29 & 1.85 & 2.58 & & & & & & & & & \\
\hline 2 & 0.14 & 0.24 & 0.38 & 0.58 & 0.87 & 1.27 & 1.81 & & & & & & & & & & \\
\hline
\end{tabular}


paracetamol in polymer, mutual miscibility of ingredients and the glass transition of mixture are compiled in Tables 3, 4. These data were used to prepare the phase diagram for physical mixture of API with hypromellose shown in Figure 6.

The glass transition curve reflects the predicted temperature at which the mixture undergoes glass transition at a given composition. Glass transition was also confirmed with the aid of the heating-cooling-heating test. DSC curves reflecting this test for mixtures containing 90, 70, 50, 30, and 10\% of API are illustrated in Figure 7. Detailed inspection of these curves revealed that melted paracetamol underwent amorphization during the fast cooling cycle (Figure 7B, curve a), a fact confirmed by an inflection on the DSC curve due to paracetamol glass transition and the absence of exothermic peak due to the crystallization of API. The performance of all the mixtures under study was the same as paracetamol behavior (Figure 7B, curves b-f).

In the second cycle of heating, the DSC curve of paracetamol (Figure 7C, curve a) showed inflection at $\sim 23^{\circ} \mathrm{C}$ caused by the glass transition. A further exothermic peak was found due to paracetamol recrystallization to polymorphic form II which melted at $\sim 160^{\circ} \mathrm{C}$. For all mixtures, the DSC curves of the second heating cycle (Figure $7 \mathrm{C}$, curves $\mathrm{b}-\mathrm{f}$ ) revealed an inflection due to glass transition between $\sim 24$ and $\sim 112^{\circ} \mathrm{C}$, respectively, for decreasing quantity of paracetamol in mixture. These temperatures are compiled in Table 4 along with those calculated using a suitable Equation (12). Neither an exothermic peak due to paracetamol crystallization nor an endothermic peak caused by its melting was found on the DSC curves of the second heating cycle. Thus, the melting of paracetamol with

TABLE 4 | Calculated temperatures of miscibility and glass transition in the mixtures of paracetamol with hypromellose.

\begin{tabular}{|c|c|c|c|c|c|c|c|}
\hline \multirow[t]{2}{*}{$\begin{array}{l}\text { Content of } \\
\text { paracetamol (\%) }\end{array}$} & \multicolumn{2}{|c|}{ Mole fraction $(x)$} & \multicolumn{2}{|c|}{ Volume fraction $(\Phi)$} & \multirow[t]{2}{*}{$\begin{array}{c}\text { Miscibility } \\
\text { temperature }\left({ }^{\circ} \mathrm{C}\right)\end{array}$} & \multicolumn{2}{|c|}{$\begin{array}{l}\text { Glass transition } \\
\text { temperature }\left({ }^{\circ} \mathrm{C}\right)\end{array}$} \\
\hline & Paracetamol & Hypromellose & Paracetamol & Hypromellose & & Calculated & DSC \\
\hline 95 & 0.9992 & 0.0008 & 0.938 & 0.062 & 2097.6 & 23.9 & \\
\hline 90 & 0.9983 & 0.0017 & 0.877 & 0.123 & 1029.3 & 25.0 & 24.13 \\
\hline 85 & 0.9973 & 0.0027 & 0.818 & 0.182 & 631.2 & 26.3 & \\
\hline 80 & 0.9962 & 0.0038 & 0.760 & 0.240 & 423.1 & 27.7 & \\
\hline 75 & 0.9950 & 0.0050 & 0.704 & 0.296 & 295.1 & 29.2 & \\
\hline 70 & 0.9936 & 0.0064 & 0.649 & 0.351 & 208.4 & 31.0 & 26.09 \\
\hline 65 & 0.9919 & 0.0081 & 0.596 & 0.404 & 145.8 & 32.9 & \\
\hline 60 & 0.9900 & 0.0100 & 0.543 & 0.457 & 98.3 & 35.1 & \\
\hline 55 & 0.9878 & 0.0122 & 0.492 & 0.508 & 61.0 & 37.6 & \\
\hline 50 & 0.9851 & 0.0149 & 0.442 & 0.558 & 30.9 & 40.6 & 30.50 \\
\hline 45 & 0.9819 & 0.0181 & 0.394 & 0.606 & 6.0 & 44.0 & \\
\hline 40 & 0.9778 & 0.0222 & 0.346 & 0.654 & -15.0 & 48.0 & \\
\hline 35 & 0.9727 & 0.0273 & 0.299 & 0.701 & -33.1 & 52.8 & \\
\hline 30 & 0.9659 & 0.0341 & 0.254 & 0.746 & -49.1 & 58.8 & 35.59 \\
\hline 25 & 0.9566 & 0.0434 & 0.209 & 0.791 & -63.6 & 66.2 & \\
\hline 20 & 0.9430 & 0.0570 & 0.166 & 0.834 & -77.1 & 75.8 & \\
\hline 19 & 0.9395 & 0.0605 & 0.157 & 0.843 & -79.8 & 78.0 & \\
\hline 18 & 0.9356 & 0.0644 & 0.148 & 0.852 & -82.5 & 80.4 & \\
\hline 17 & 0.9313 & 0.0687 & 0.140 & 0.860 & -85.2 & 83.0 & \\
\hline 16 & 0.9265 & 0.0735 & 0.131 & 0.869 & -88.0 & 85.7 & \\
\hline 15 & 0.9211 & 0.0789 & 0.123 & 0.877 & -90.8 & 88.6 & \\
\hline 14 & 0.9150 & 0.0850 & 0.114 & 0.886 & -93.7 & 91.7 & \\
\hline 13 & 0.9081 & 0.0919 & 0.106 & 0.894 & -96.6 & 95.0 & \\
\hline 12 & 0.9002 & 0.0998 & 0.098 & 0.902 & -99.8 & 98.6 & \\
\hline 11 & 0.8910 & 0.1090 & 0.089 & 0.911 & -103.0 & 102.5 & \\
\hline 10 & 0.8802 & 0.1198 & 0.081 & 0.919 & -106.5 & 106.7 & 60.44 \\
\hline 9 & 0.8674 & 0.1326 & 0.073 & 0.927 & -110.4 & 111.2 & \\
\hline 8 & 0.8519 & 0.1481 & 0.065 & 0.935 & -114.6 & 116.1 & \\
\hline 7 & 0.8328 & 0.1672 & 0.056 & 0.944 & -119.4 & 121.5 & \\
\hline 6 & 0.8085 & 0.1915 & 0.048 & 0.952 & -125.1 & 127.4 & \\
\hline 5 & 0.7769 & 0.2231 & 0.040 & 0.960 & -132.0 & 133.9 & 112.34 \\
\hline 4 & 0.7338 & 0.2662 & 0.032 & 0.968 & -140.8 & 143.5 & \\
\hline 3 & 0.6717 & 0.3283 & 0.024 & 0.976 & -152.8 & 152.5 & \\
\hline 2 & 0.5745 & 0.4255 & 0.016 & 0.984 & -170.8 & 162.8 & \\
\hline
\end{tabular}




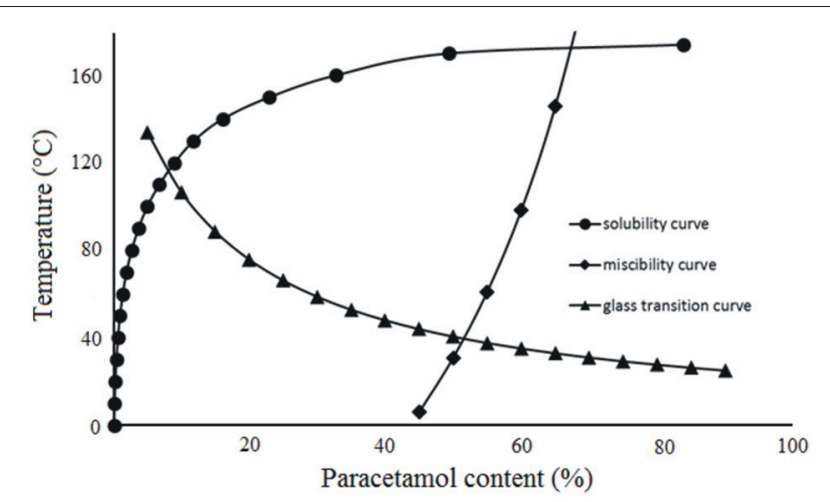

FIGURE 6 | Phase diagram for paracetamol binary mixtures with hypromellose.

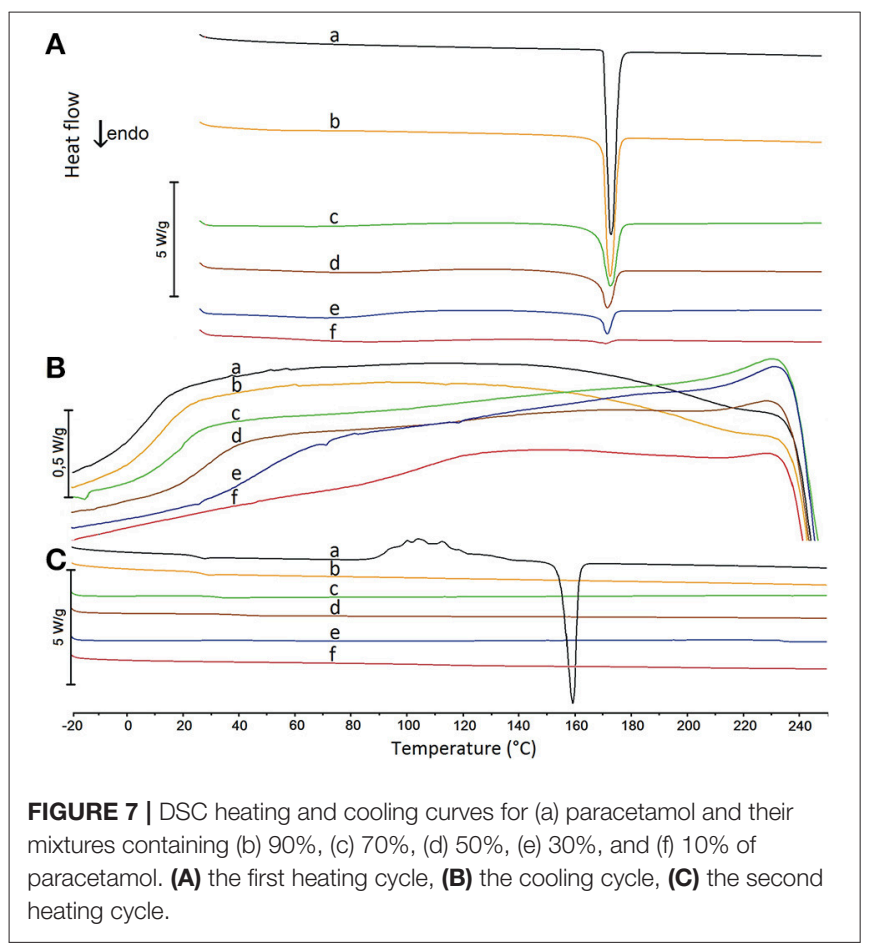

hypromellose lead to amorphization of API with inhibition of its crystallization.

The phase diagram permits a prediction of the thermodynamic stability of the system containing API and hypromellose in relation to temperature (Djuris et al., 2013; Tian

\section{REFERENCES}

Adhikari, K., Flurchick, K. M., and Valenzano, L. (2015). Effects of volumetric in molecular crystals: a quantum mechanical investigation on aspirin and paracetamol most stable polymorphs. Chem. Phys. Let. 621, 109-116. doi: 10.1016/j.cplett.2014. et al., 2015). Figure 6 shows that the area above the solubility curve is the thermodynamically stable region, while the area between the miscibility and solubility curves represents the thermodynamically unstable region in which spontaneous phase separation may occur. In addition, the area on the right-side of the miscibility curve indicates the region in which ingredients are separated. The glass transition curve represents the glass transition temperatures for paracetamol-hypromellose mixtures.

\section{CONCLUSIONS}

DSC studies of paracetamol mixtures with hypromellose revealed potential interaction between ingredients that resulted in a reduction of paracetamol crystallinity. This was confirmed using a heating-cooling-heating cycle-fast cooling of paracetamol mixture with hypromellose caused the amorphization of paracetamol, while crystallization of API was inhibited in the presence of the polymer. There is a greater risk of initiating interactions when the homogenization of mixtures is carried out using a pestle. FT-IR and Raman investigations excluded chemical reaction and hydrogen bonding between API and polymer. Furthermore, HSM research indicated that neither new crystals nor amorphous particles were found when mixtures were heated.

The phase diagram developed for paracetamol mixtures with hypromellose allows us to forecast to what extent API dissolves in the polymer. The phase diagram also reflects the mutual miscibility of ingredients as well as the temperature and composition of mixture at which the system should be physically stable.

\section{DATA AVAILABILITY STATEMENT}

The datasets generated for this study are available from the authors.

\section{AUTHOR CONTRIBUTIONS}

MW and EL conceived and designed experiments. EL conducted experiments and analyzed data. MW and EL wrote the manuscript. All authors read and approved the manuscript.

\section{FUNDING}

This research was supported by the Ministry of Science and Higher Education, Poland, grants numbers 01-0218/08/505 and 01-0363/08/505. 
Bajdik, J., Baki, G., Szent-Királlyi, Z., Knop, K., Kleinebudde, P., and PintyeHódi, K. (2008). Evaluation of the composition of the binder bridges in matrix granules prepared with a small-scale high-shear granulator. J. Pharm. Biomed. Anal. 48, 694-701. doi: 10.1016/j.jpba.2008.06.023

Bennett, P. N., and Brown, M. J. (2008). Clinical Pharmacology, 10th Edn. Edinburgh: Churchill Livingstone; Elsevier

Bhise, S. B., and Rajkumar, M. (2008). Effect of HPMC on solubility and dissolution of carbamazepine form III in simulated gastrointestinal fluids. Asian J. Pharm. 2, 38-42. doi: 10.4103/0973-8398.41564

Bi, M., Hwang, S.-J., and Morris, K. R. (2003). Mechanism of eutectic formation upon compaction and its effects on tablet properties. Thermochim. Acta 404, 213-226. doi: 10.1016/S0040-6031(03)00185-0

Burgina, E. B., Baltakhinov, V. P., Boldryeva, E. V., and Shakhtschneider, T. P. (2004). IR spectra of paracetamol and phenacetin. J. Struct. Chem. 45, 64-73. doi: 10.1023/B:JORY.0000041502.85584.d5

Byard, S. J., Jackson, S. L., Smail, A., Bauer, M., and Apperley, D. (2005). Studies on the crystallinity of a pharmaceutical development drug substance. J. Pharm. Sci. 94, 1321-1335. doi: 10.1002/jps.20328

Chan, A., Coppens, K., Hall, M., He, V., Jog, P., Larsen, P., et al. (2006). “Solubility parameters as a tool to predict API morphology in hot-melt extruded (HME) formulations containing ethylcellulose, hypromellose and polyethylene oxide," in Poster Presented at the 2006 Annual Meeting Exposition of the American Association of Pharmaceutical Scientists (San Antonio, TX).

Chonkar, A. D., Rao, J. V., Managuli, R. S., Mutalik, S., Dengale, S., Jain, P., et al. (2016). Development of fast dissolving oral films containing lercanidipine HCI nanoparticles in semicrystalline polymeric matrix for enhanced dissolution and ex vivo permeation. Eur. J. Pharm. Biopharm. 103, 179-191. doi: 10.1016/j.ejpb.2016.04.001

Curtin, V., Amharar, Y., Gallagher, K. H., Corcoran, S., Tejber, L., Corrigan, O. I., et al. (2013). Reducing mechanical activation-induced amorphisation of salbutamol sulphate by co-processing with selected carboxylic acids. Int. J. Pharm. 456, 508-516. doi: 10.1016/j.ijpharm.2013.08.025

de Oliveira, G. G. G., Feitosa, A., Loureiro, K., Fernandes, A. R., Souto, E. B., and Severino, P. (2017). Compatibility study of paracetamol, chlorpheniramine maleate and phenylephrine hydrochloride in physical mixtures. Saudi Pharm. J. 25, 99-103. doi: 10.1016/j.jsps.2016.05.001

Djuris, J., Nikolakakis, I., Ibric, S., Djuric, Z., and Kachrimanis, K. (2013). Preparation of carbamazepine-Soluplus solid dispersions by hot-melt extrusion, and prediction of drug-polymer miscibility by thermodynamic model fitting. Eur. J. Pharm. Biopharm. 84, 228-237. doi: 10.1016/j.ejpb.2012.12.018

Espeau, P. ,Ceolin, R., Tamarit, J.-L., Perrin, M.-A., Gauchi, J.-P., and Leveiller, F. (2005). Polymorphism od paracetamol: relative stabilities of the monoclinic and orthorhombic phases inferred from topological pressure-temperature and temperature-volume phase diagrams. J. Pharm. Sci. 94, 524-538. doi: $10.1002 /$ jps.20261

Ford, J. L. (1999). Thermal analysis of hydroxypropylmethylcellulose and methylcellulose: powders, gels and matrix tablets. Int. J. Pharm. 179, 209-228. doi: 10.1016/S0378-5173(98)00339-1

Ford, J. L., and Mitchell, K. (1995). Thermal analysis of gels and matrix tablets containing cellulose ethers. Thermochim. Acta 248, 329-345. doi: 10.1016/0040-6031(94)01954-F

Forster, A., Hempenstall, J., Trucker, I., and Rades, T. (2001). Selection of excipients for melt extrusion with two poorly water-soluble drugs by solubility parameter calculation and thermal analysis. Int. J. Pharm. 226, 147-161. doi: 10.1016/S0378-5173(01)00801-8

Friedrich, H., Nada, A., and Bodmeier, R. (2005). Solid state and dissolution rate characterization of co-ground mixtures of nifedipine and hydrophilic carriers. Drug Dev. Ind. Pharm. 31, 719-728. doi: 10.1080/03639040500216097

Giordano, F., Rossi, A., Bettini, R., Savioli, A., Gazzaniga, A., and Novák, C. S. (2002). Thermal behavior of paracetamol polymeric excipients mixtures. $J$. Therm. Anal. Calorim. 68, 575-590. doi: 10.1023/A:1016004206043

Hino, T., and Ford, J. L. (2001). Characterization of the hydroxypropylmethylcellulose-nicotinamide binary system. Int. J. Pharm. 219, 39-49. doi: 10.1016/S0378-5173(01)00619-6

Jahangiri, A., Barzegar-Jalali, M., Garjani, A., Javadzadeh, Y., Hamishehkar, H., Afroozian, A., et al. (2015). Pharmacological and histological examination of atorvastatin-PVP K30 solid dispersions. Powd. Technol. 286, 538-545. doi: 10.1016/j.powtec.2015.08.047

Katzhendler, I., Azoury, R., and Friedman, M. (1998). Crystalline properties of carbamazepine in sustained release hydrophilic matrix tablets based on hydroxypropyl methylcellulose. J. Control. Rel. 54, 69-85. doi: 10.1016/S0168-3659(98)00002-9

Klìmová, K., and Leitner, J. (2012). DSC study and phase diagrams calculation of binary systems of paracetamol. Thermochim. Acta 550, 59-64. doi: 10.1016/j.tca.2012.09.024

Liu, Z.-P., Zhang, L.-L., Yang, Y.-Y.,Wu, D., Jiang, G., and Yu, D.-G. (2018). Preparing composite nanoparticles for immediate drug release by modifying electrohydrodynamic interfaces during electrospraying. Powd. Technol. 327, 179-187. doi: 10.1016/j.powtec.2017.12.066

Locatelli, M., Cifelli, R., Di Legge, C., Barbacane, R. C., Costa, N., Fresta, M., et al. (2015). Simultaneous determination of eperisone hydrochloride and paracetamol in mouse plasma by high performance liquid chromatography-photodiode array detector. J. Chrom. A 1388, 79-86. doi: 10.1016/j.chroma.201502.008

Łuczak, A., Jallo, L. J., Dave, R. D., and Iqbal, Z. (2013). Polymorph stabilization in processed acetaminophen powders. Powd. Technol. 236, 52-62. doi: 10.1016/j.powtec.2012.05.046

Maniruzzaman, M., Islam, M. T., Moradiya, H. G., Halsey, S. A., Slipper, I. J., Chowdhry, B. Z., et al. (2014). Prediction of polymorphic transformations of paracetamol in solid dispersions. J. Pharm. Sci. 103, 1819-1828. doi: $10.1002 /$ jps. 23992

Marsac, P. J., Shamblin, S. L., and Taylor, L. S. (2006). Theoretical and practical approaches for prediction of drug-polymer miscibility and solubility. Pharm. Res. 10, 2417-2426. doi: 10.1007/s11095-006-9063-9

Meng, F., Dave, V., and Chauhan, H. (2015). Qualitative and quantitative methods to determine miscibility in amorphous drug-polymer systems. Eur. J. Pharm. Sci. 77, 106-111. doi: 10.1016/j.ejps.2015.05.018

Oh, C. M., Heng, P. W. S., and Chan, L.W. (2015). Influence of hydroxypropyl methylcellulose on metronidazole crystallinity in spray-congealed polyethylene glycol microparticles and its impact with various additives on metronidazole release. AAPS PharmSciTech. 16, 1357-1367. doi: 10.1208/s12249-015-0320-2

Raghavan, S. L., Trividic, A., Davis, A. F., and Hadgraft, J. (2001). Crystallization of hydrocortisone acetate: influence of polymers. Int. J. Pharm. 212, 213-221. doi: 10.1016/S0378-5173(00)00610-4

Rossi, A., Savioli, A., Bini, M., Capsoni, D., Massarotti, V., Bettini, R., et al. (2003). Solid-state characterization of paracetamol metastable polymorphs formed in binary mixtures with hydroxypropylmethylcellulose. Thermochim. Acta 406, 55-67. doi: 10.1016/S0040-6031(03)00227-2

Rowe, R. C., Sheskey, P. J., and Quinn, M. E. (2009). Handbook of Pharmaceutical Excipients, 6th Edn. London: Pharmaceutical Press.

Sakata, Y., Shiraishi, S., and Otsuka, M. (2006). A novel white film for pharmaceutical coating formed by interaction of calcium lactate pentahydrate with hydroxypropyl methylcellulose. Int. J. Pharm. 317, 120-126. doi: 10.1016/j.ijpharm.2006.02.058

Salunkhe, N. H., Jadhav, N. R., More, H. N., and Jadhav, A. D. (2018). Screening of drug-sericin solid dispersions for improved solubility and dissolution. Int. J. Biol. Macromol. 107, 1683-1691. doi: 10.1016/j.ijbiomac.2017.10.035

Sibik, J., Sargent, M. J., Franklin, M., and Zeitler, J. A. (2014). Crystallization and phase changes in paracetamol from the amorphous solid to the liquid phase. Mol. Pharm. 11, 1326-1334. doi: 10.1021/mp400768m

Siepmann, J., and Peppas, N. A. (2001). Modeling of drug release from delivery systems based on hydroxypropyl methylcellulose (HPMC). Adv. Drug Deliv. Rev. 48, 139-157. doi: 10.1016/S0169-409X(01) 00112-0

Steger, N., Aucamp, M., Zhang, S.-W., and de Villiers, M. M. (2012). Hot-stage optical microscopy as an analytical tool to understand solid-state changes in pharmaceutical materials. Am. Pharm. Rev. 15, 32-36.

Subhashree, S., Kanti, C. H., Chandra, M. S., and Sharmistha, N. (2011). Qualitative analysis of controlled release ofloxacin/HPMC mucoadhesive suspension. Int. J. Drug Dev. Res. 3, 3217-3232.

Tian, B., Wang, X., Zhang, Y., Zhang, K., Zhang, Y., and Tang, X. (2015). Theoretical prediction of a phase diagram for solid dispersions. Pharm. Res. 32, 840-851. doi: 10.1007/s11095-014-1500-6 
Wen, H., Morris, K. R., and Park, K. (2005). Hydrogen bonding interactions between adsorbed polymer molecules and crystal surface of acetaminophen. J. Colloid Interf. Sci. 290, 325-335. doi: 10.1016/1.jcis.0.2005. 04.049

WHO Collaborating Centre for Drug Statistics Methodology (2018). Available online at: https://www.whocc.no/atc_ddd_index/ (Accessed December 10, 2018)

Yao, R., Xu, J., Lu, X., and Deng, S. (2011). Phase transition behaviour of HPMCAA and preparation of HPMC-PAA nanogels. J. Nanomat. 2011:507542. doi: 10.1155/2011/507542

Zaini, E., Sherry, A., Agustin, W., and Agustin, R. (2014). Enhancement of dissolution rate of meloxicam by co-grinding technique using hydroxypropyl methylcelulose. J. Chem. Pharm. Res. 11, 263-267.

Zhang, Q., Zhao, Y., Zhao, Y., Ding, Z., Fan, Z., Zhang, H., et al. (2018). Effect of HPMCAS on recrystallization inhibition of nimodipine solid dispersions prepared by hot-melt extrusion and dissolution enhancement of tablets. Colloids Surf. B Biointerf. 172, 118-126. doi: 10.1016/j.colsurfb.2018. 08.030

Conflict of Interest Statement: The authors declare that the research was conducted in the absence of any commercial or financial relationships that could be construed as a potential conflict of interest.

Copyright (C) 2019 Leyk and Wesolowski. This is an open-access article distributed under the terms of the Creative Commons Attribution License (CC BY). The use, distribution or reproduction in other forums is permitted, provided the original author(s) and the copyright owner(s) are credited and that the original publication in this journal is cited, in accordance with accepted academic practice. No use, distribution or reproduction is permitted which does not comply with these terms. 